\title{
Investigation of the role of spatial evolution in a 2-D reactive transport simulation of the oxalate carbonate pathway
}

\author{
HANNAH GATZ-MILLER ${ }^{1}$, DANYANG SU ${ }^{1}$, FRÉDÉRIC \\ GÉRARD ${ }^{2}$, ERIC VERRECCHIA ${ }^{3}$ AND K. ULRICH \\ MAYER $^{1}$
}

${ }^{1}$ University of British Columbia

${ }^{2}$ INRAE

${ }^{3}$ University of Lausanne

Presenting Author: hmiller@eoas.ubc.ca

Previous research suggests that local soil $\mathrm{pH}$ increase around the roots and acidic soil of the Iroko tree is a consequence of the oxalate carbonate pathway (OCP), which can result in the biologically facilitated sequestration of carbon that has been absorbed by the tree during photosynthesis. Bacterially mediated oxidation of calcium oxalate from the fallen plant tissue causes a localized soil $\mathrm{pH}$ increase and development of a soil environment that may support calcite precipitation in areas previously devoid of carbonate rocks.

A plot-scale sensitivity analysis of the OCP with a reactive transport (RT) model has successfully modeled the suggested mechanism of the OCP. The plot-scale RT model, focused on the mass balance, suggests that a variety of different $\mathrm{Ca}$ sourcing scenarios may facilitate carbonate mineral formation in a quantity on par with that observed in the field. These model results have also suggested that both lateral and vertical spatial distribution of roots, fluctuating accessibility of roots to $\mathrm{Ca}$, and the growing extent of the foliar crown, may all play important roles in determining the magnitude, distribution, and timing of both the soil $\mathrm{pH}$ change and calcite precipitation.

Following, a 2-D model has been constructed in order to investigate the relationship between $\mathrm{Ca}$ availability in soil and the lateral root distribution that the 1-D models have suggested to be integral to the OCP mechanism, using the RT code MIN3P$\mathrm{THCm}$. Capable of representing both a vertical soil column and lateral root extent, the 2-D model focuses on the relationship between changing lateral root distribution through time, $\mathrm{Ca}$ accumulation by the tree, and Ca-oxalate loss from the tree through time. In addition to the mass balance, the focus of the 2D model, with varying root extent, is to assess the evolution of the soil $\mathrm{pH}$ gradient proximal to the tree, as well as the possible spatial distribution of calcite precipitation in the surrounding soil. 